\title{
Mobile Braille Touch Application for Visually Impaired People using Double Diamond Approach
}

\author{
Rony Aldhea Dwi Cahya ${ }^{1, *}$, Anik Nur Handayani ${ }^{1}$, and Aji Prasetya Wibawa ${ }^{1}$ \\ ${ }^{1}$ Universitas Negeri Malang, Electrical Engineering Department, Engineering Faculty, 65145, Malang, Indonesia
}

\begin{abstract}
Reading and writing in Braille learning using technology for visually impaired people has been available in various forms. One of Braille learning has been developed using smartphone is Mobile Braille Touch (MBT) application. MBT developed is far from perfect, system on MBT still use static keyboard. The button touch in MBT is not effective, so the user cannot touch the button properly. Therefore, Mobile Braille Touch application further developed based on user experiences (UX) correspond with user needs. In this research, we use a Double Diamond method which consists of (1) Discover, (2) Define, (3) Develop, (4) Delivery. The result of this research is developing of new Virtual Braille Keyboard (VBK) that called as dynamic keyboard. This VBK consist of dynamic dot braille and swipe writing assisted button.
\end{abstract}

\section{Introduction}

Media that used by visual impairment people to obtain information and communicate with others using Braille. According to Indonesian Dictionary, called KBBI, Braille is a writing and print system (based on the Latin alphabet) for the visually impaired people [1]. Code on braille consists of 6 points with various combinations emerged on the paper so that it can be touched. Learning to use Braille letters for the Blind is available in various forms, one of them by using the Plate Board (Braille Text). Lessons using this Plate Board cannot be used mobile, has a large size and blunt spikes prone to disappear [2]. Technology began to evolve and learning using Braille letters began to be developed using computer technology [3]. There are some Braille learning media supporters that use computer technology such as JAWS (Job Access with Speech), a software to help the visually impaired use of computers on the Windows Operating System developed by Blind and Low Vision Group in American Foundation for The Blind [4]. Besides that, another braille learning media is Refreshable Braille development results from Google 2012 which is Braille keyboard hardware to assist in writing and reading and support of Braille Back applications in Smartphones [5].

Mobile Braille Touch Application (MBT), braille reading and writing application for the Blind [2]. This app uses Smartphone as the main device with Virtual Braille Keyboard (VBK) design as input of dot braille combination to write. The operating system used is Android with a minimum version 4.2 (Jelly Bean). This operating system is very popular for users of smartphone with the benefits of user friendly and simple design. VBK design that generated $2 \times 3$ buttons are placed on the right and left side of the smartphone with landscape screen orientation. The length of the dot braille button on
VBK is made static adjusted to the length of the size of a human finger segment from the middle finger to the fingertip of an average of $\pm 3.7 \mathrm{~cm} \mathrm{[6].} \mathrm{The} \mathrm{trial} \mathrm{of} \mathrm{MBT}$ application by measuring the speed of writing using VBK resulted in Text Entry Rate with a Word Per Minute (WPM) of 5.05 WPM better than Joao Oilveira (2011) research which is 1.45 WPM [7]. The next MBT application development is tailored to the needs of users (as required) according to field observation results.

\section{Related work}

The Mobile Braille Touch application has the main goal to helping users, especially blind students to learn Braille letters. The main page view of MBT application according to Figure 1.

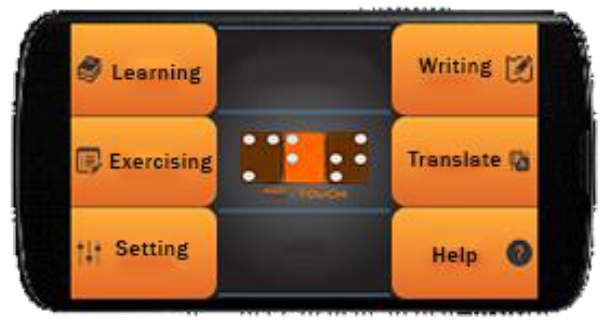

Fig. 1. Mobile braille touch application display [2]

Mobile Braille Touch application has voice narrator that will help the users, especially the visually impaired people in using the application. The narrator's voice is using Google's Text to Speech technology. In the Mobile Braille Touch application, there are 6 main features namely Learning, Exercise, Writing, Translation, Settings, and Help. In addition, there are additional features that feature Speed Writing Compute.

In the design of Virtual Braille Keypad on the Braille Touch Mobile application, there are 6 buttons with $3 \times 2$ binary matrix arrangement according to figure 1 . The

\footnotetext{
* Corresponding author: rony.aldheade@gmail.com
} 
description of the design of Virtual Braille Keypad is as follows:

- Space bar, Enter, and Backspace are located in the middle of the top. When need to write, the user will use writing place that placed in the middle of the area. Next, for additional menu (reset, help and back) at the bottom of the screen. This area called as writing menu

- There is feedback in the form of a combination of Braille letters that have been entered.

- To select a menu such as spaces, Enter, Back Space, and others with long press on the key while to press 1 time on the button the application will issue a sound from the name of the button.

- Time Delay used for interval time in confirming button is 1 second

The functional design of Virtual Braille Keyboard in the Mobile Braille Touch application positioned the dot braille buttons on the right and left of the smartphone screen. This position makes it easier for users when using the app with a three-finger grip on the right and left edge of the smartphone. The location of each finger on the braille dot braille Mobile Braille Touch application:

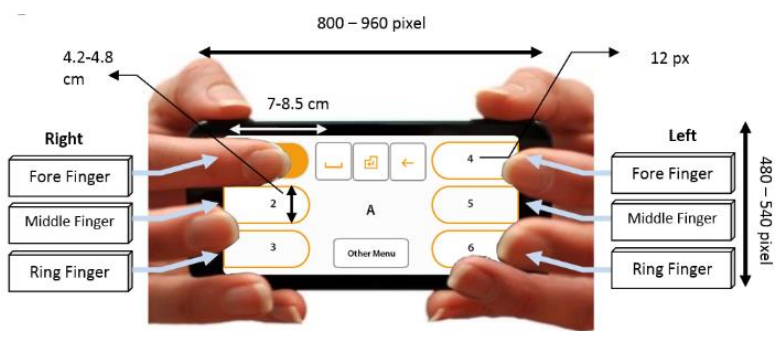

Fig. 2. Layout button and finger on dot braille [2].

The button size is made static is about $3.7 \mathrm{~cm}$. It is the average of human finger. The development of this dot braille is called as static dot braille. Virtual Braille Keyboard also has some additional function buttons to help write, such as space bar, enter, and backspace. The results of previous testing using the Mobile Braille Touch application, some users have trouble using other menu buttons such as the space bar enter, and backspace because the laying of the button is in the middle of the virtual keyboard, the user must press the button in longtime $(1200 \mathrm{~ms})$ as well as a size that is not so great. The results of the Virtual Braille Keyboard design functional test get the Text Entry Rate (in a Word Per Minute) when using the Virtual Braille Keyboard design on the Smartphone of 5.05 WPM. Another disadvantage is that applications are difficult to use if the user's smartphone screen size is too small \pm 3 inches or too large \pm 7 inches because of the size of the optimal Virtual Braille Keypad design used on screen sizes \pm 4-6

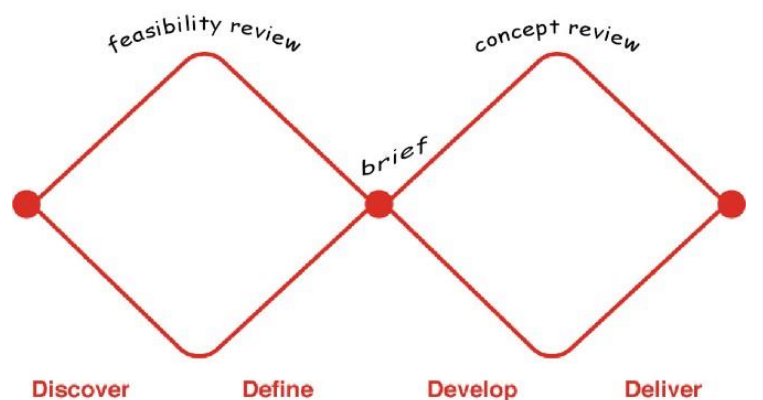

inches. The material database and problems in the MBT application are static so they cannot be changed as desired unless a subsequent update is made to change or add to the database in the application.

\section{Methodology}

Fig. 3. Double diamond.

The research procedure used Double Diamond method developed by the British Design Council (2005). This development method consists of 4 stages of Discover, Define, Develop, and Deliver. Selection of this development method is because this method is done systematically starting from the initial identification of user needs, problem limitation, finding solution, then develop the product in the form of prototype. Another reason for using this method is the Deliver stage at the end, which is used to test and evaluate the development results in prototype form. The steps of this method involve the following stages of the project:

\subsection{Discover}

Discover is a process to explore insights about a problem to be solved. This stage is divergent, which aims to identify and understand the initial problem of research. Identify problems by conducting interviews and trials to find out the problems facing previous users

\subsection{Define}

The second stage is Define which has convergent properties. Define is a process to determine the area to be centered. This stage aims to limit and define the obvious problem in order to be resolved. The results of this stage then used as a reference to find a solution in the development of User Experiences.

\subsection{Develop}

The next stage is Develop. Develop is a process to design a solution to be developed This stage is divergent. The purpose of this stage is to find solutions and problems that already exist. Solutions that can be done at this stage include workflow design, system design, and functionality design.

\subsection{Delivery}

Deliver is the last stage in the Double Diamond development method. Deliver is convergent on the part of the process to implement the found solution. This stage aims to test and evaluate concepts in the production and launch processes. Launch is done by testing the application development results to the target users of the application. The results of the application test are used as reference for future development.

\section{Result and discussion}


This research was conducted using User Experiences (UX) approach. Basic selection of this method is due to adjust to the needs of the target user learning applications based on the results of observation and user needs interviews (User Needs). The development results using the Double Diamond method are:

\subsection{Discover}

The Discover stage aims to identify and understand the initial problem of the study. At this stage, problem identification is done through the first Mobile Braille Touch application test. The initial observation was conducted on February 10, 2017 at 8:00 am - 10:00 am in UPT Sosial dan Cacat Netra (RSCN) Malang. The Mobile Braille Touch application test is done in the A preparatory class (Braille Reading Basics learning class) consisting of 20 students. In addition to the first version of the Mobile Braille Touch application test, the problem identification is done by interviewing the instructor to find out the problems in Braille Reading Lesson learning using the Braille Touch Mobile App. Interview conducted with Drs. R. Budiono, SE, S. Sos. as a Preparation Class Teacher A.

Observation result on UPT Blind Malang RSCN in Preparation Class A (initial preparation class for learning Read Braille). From the observation to 25 students, 90\% expressed interest in using the application in learning. In other reason, $82 \%$ say the use of Mobile Braille Touch applications are difficult to operate. This difficulty is due to several factors experienced when using the Mobile Braille Touch application, hi (1) the students stated need assistance when using the application, (2) the keyword in the mobile signature display is not comfortable with static dot keyboard, and (3) the student stated such position what is meant, incoming, and backspace is difficult to achieve. Based on these observations, it is necessary to develop a Mobile Braille Touch application that is adapted to the user needs that is Preparatory Class A students in UPT RSCN Malang. The situation will be developed by UX approach, concern to user needs.

\subsection{Define}

The define stage aims to limit and define the obvious problems that must be resolved. This stage is a continuation of the Discover stage used to determine the problem to be solved. Based on the results of application tests to students and interviews with teachers, there are two main problems to be resolved presented in the comparison table 1 below.

Table 1. Comparison point of application development.

\begin{tabular}{|l|l|l|}
\hline Indicator & \multicolumn{1}{|c|}{ V1 } & \multicolumn{1}{c|}{ V2 } \\
\hline $\begin{array}{l}\text { Dot braille } \\
\text { button }\end{array}$ & $\begin{array}{l}\text { Static dot } \\
\text { braille }\end{array}$ & $\begin{array}{l}\text { Dynamic dot } \\
\text { braille }\end{array}$ \\
\hline $\begin{array}{l}\text { Writing Assist } \\
\text { button }\end{array}$ & Static button & Swipe screen \\
\hline
\end{tabular}

\subsection{Develop}

Develop stage aims to focus on finding solutions and problems that already exist. This stage is the completion of the Define stage to determine the solution to a defined problem. Further solution will be done that is by designing: (1) Application Work Flow Diagram; (2) Virtual Braille Keyboard Design with dynamic touch; (3) Design Help Button Writing.

\subsubsection{Application workflow diagram}

The workflow diagram design of learning media Braille letters is shown in Figure 4.

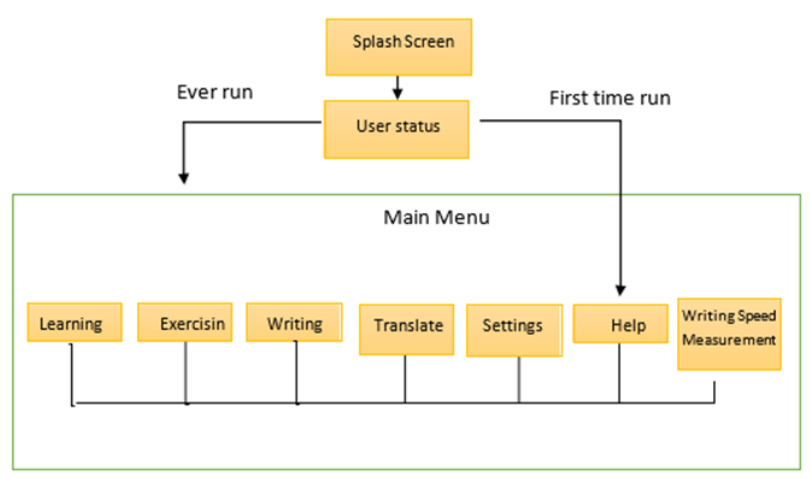

Fig. 4. Workflow chart media.

\subsubsection{Virtual braille keyboard design}

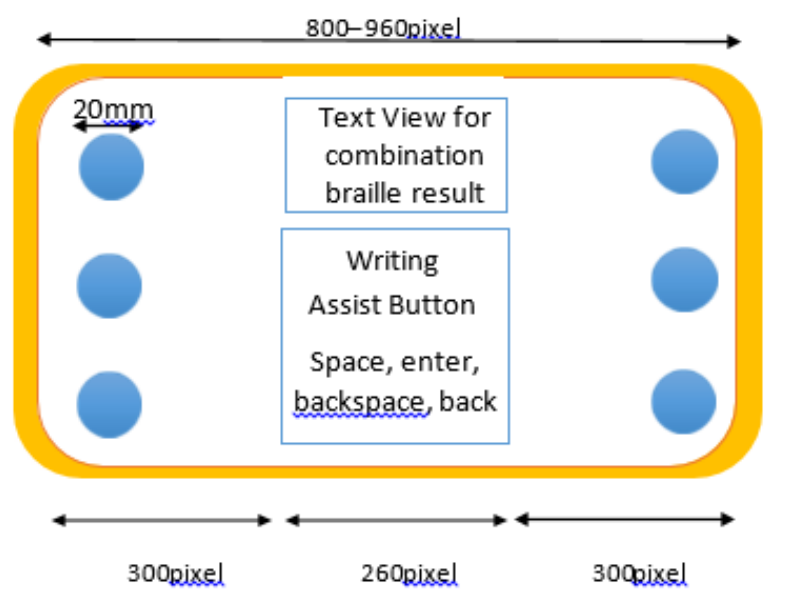

Fig. 5. Virtual braille keyboard design.

Based on Figure 5 the size of each key that used in Virtual Braille Keyboard has a diameter of $25 \mathrm{~mm}$. This button size is obtained based on the MIT Touch Lab Study, study on Sensor Mechanics Average size of an adult human finger is $16-20 \mathrm{~mm}$ (45 - 57 pixels) [9]. To determine the button of $25 \mathrm{~mm}$ wider than the average width of the human finger, is connected with the Law Fitts (1954) about Human Computer Interaction which states that the greater the size of the object the greater the accuracy and the time required to access the target. 
Replace the writing assist button function into the swipe screen function. The use of a swipe screen is based on write-writing button functions such as spaces, enter, and backspace.

- Assist button for space using right swipe screen

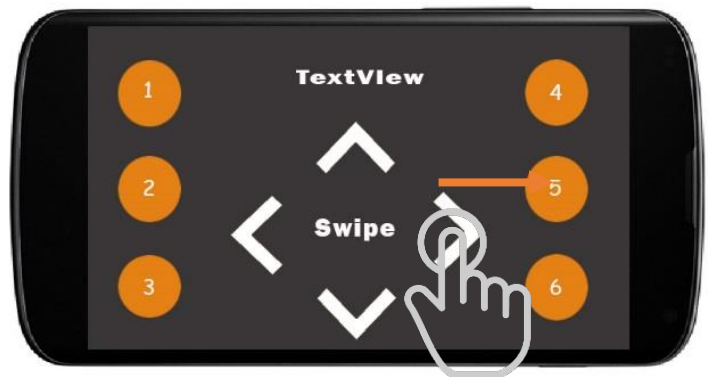

Fig. 6. Right swipe for space.

- Assist button for backspace using left swipe screen

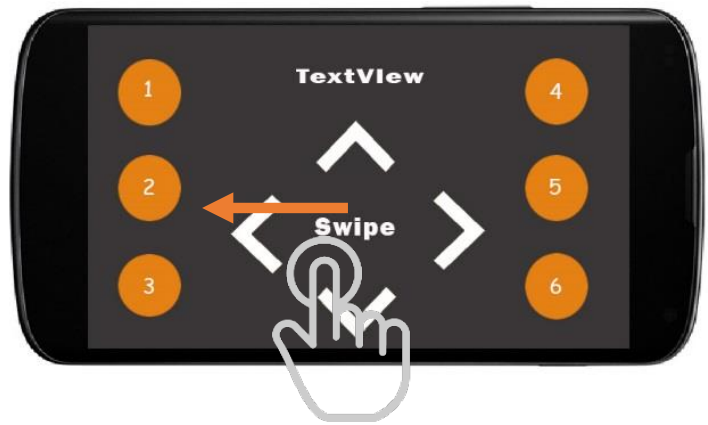

Fig. 7. Left swipe for backspace.

- Assist button for enter using bottom swipe screen

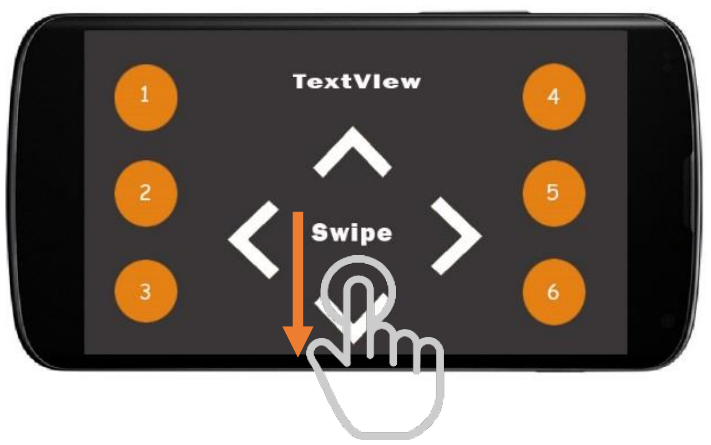

Fig. 8. Down swipe for enter.

\subsubsection{Mobile braille touch menu}

The MBT application consists of six main features: Learning, Exercise, Writing, Translation, Settings, and Help. In addition to these six features, there is an additional feature for the evaluation of the write speed of the Feature Speed Compute Feature.

\section{- Learning menu}

The MBT in-app learning feature is a feature for learning Braille letters. The display of learning features in MBT applications can be seen in Figure 9. In this feature, use a spotlight library that has a working system as a tutorial.
The tutorial in this feature will help the user in learning the dot braille combination in each material. The material presented in this feature includes learning letters; numbers; punctuation; double, word, and sentence; and mathematics.

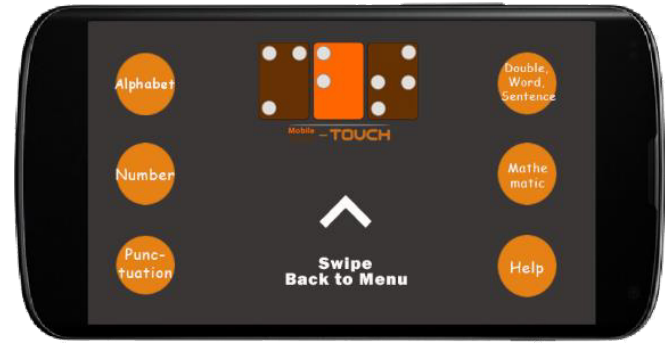

Fig. 9. Learning menu.

\section{- Exercising menu}

Features Exercises in MBT applications are used to train students in writing Braille letters by answering the questions that appear in the application. In this feature, provided some packet of questions taken from the database about Braille letters. This feature also comes with an evaluation and timer to provide time constraints when answering the questions that are displayed in the application. This feature is shown in figure 10 .

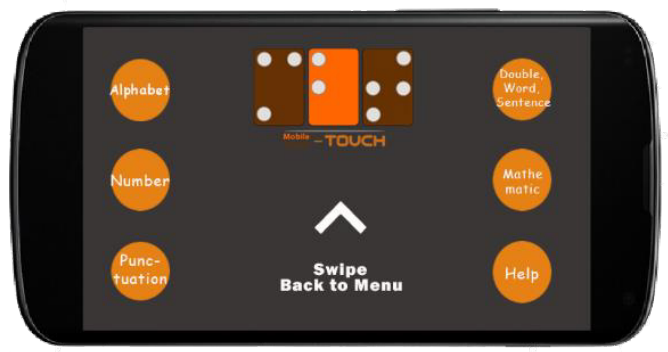

Fig. 10. Exercising menu.

- Translate menu

The Translated feature of the MBT app is used to help user alerts in learning Braille. There are two kinds of translation feature that is translated from user voice to braille (in the form of narrator voice) and Braille combination to sound. The view of the translation feature can be seen in Figure 11.

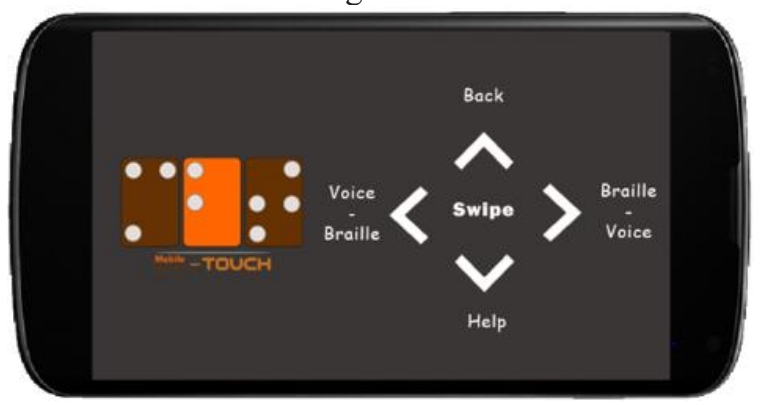

Fig. 11. Translate menu.

- Writing Menu

The Writing feature is a feature used to train users in writing Braille. In this feature comes with the design of Virtual Braille Keyboard (VBK) that is dynamic. The 
menu page display in the Writing feature can be seen in Figure 12. The VBK design comes with 6 Braille dots and writing help buttons. The write help button consists of spaces, line breaks, and backspace. Users can access this write help button by using the swipe function on the screen. Explanation of the swipe function on this feature, described in the discussion of Virtual Braille Keyboard Design.

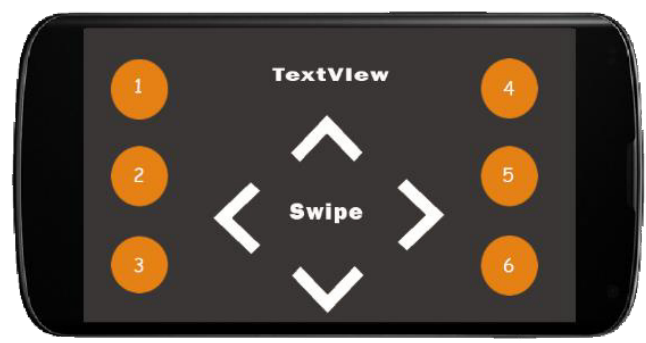

Figure 12. Writing menu.

\section{- Setting Menu}

The Settings feature in the MBT application is used to adjust the speed of feedback in the form of a narrator's voice. Narrator's voice speed is adjusted according to the level of voice grouping from very slow, slow, normal, fast and very fast. Display feature settings can be seen in Figure 13.

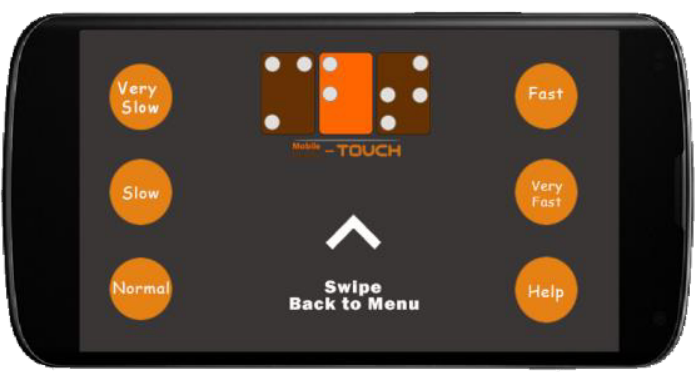

Figure 13. Setting menu.

\section{- Help menu}

The Help feature is used to assist users in using the app. This feature is helpful for users who have recently used the MBT app for learning. In this feature, users are guided using tutorials and there is a narrator's voice to help navigate to other buttons or menus. The Help feature can be seen in Figure 14.

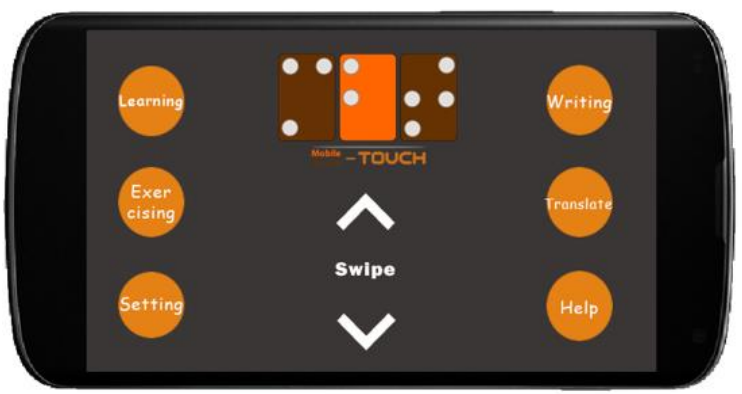

Fig. 14. Help menu.
Development of Mobile Braille Touch (MBT) application using User Experiences (UX) approach is based on user needs (User Needs) to facilitate the use of MBT applications.

The development is focused on two things. The first is changing the dot braille from static to dynamic. The second is replacing static writing assist button into a swipe screen. MBT was developed based on user needs.

\section{References}

1. Departemen Pendidikan Nasional, Kamus Besar Bahasa Indonesia (2000)

2. M R Kurniawan, Mobile Braille Touch (MBT): Pengembangan Aplikasi Media Belajar Huruf Braille berbasis Android Untuk Penyandang Tunanetra (2015)

3. T. Widiyaningtyas, L. D. Astuti, Aplikasi Media Pembelajaran Pengenalan Huruf Braille Berbasis Komputer, Semin. Electr. Informatic, Educ. (2011)

4. A. F. T. Blind, JAWS (Job Access with Speech) for Windows (Professional), [Online] Available: https://www.afb.org/prodProfile.asp?ProdID=117

5. A. Russomanno, S. O’Modhrain, R. B. Gillespie, M. W. M. Rodger, Refreshing refreshable braille displays, IEEE Trans. Haptics 8, 3, 287-297 (2015)

6. A. Buryanov and V. Kotiuk, Proportions of Hand Segments Int. J. Morphol. 28, 3, 755-758 (2010)

7. J. Oliveira, H. Nicolau, D. Gonçalves, Blind People and Mobile Touch-based Text-Entry: Acknowledging the Need for Different Flavors (2011)

\section{Conclusion}

